\title{
Exposure to Environmental Toxins in Mothers of Children with Autism Spectrum Disorder
}

\author{
Sun Mi Kim ${ }^{1}$ \\ Doug Hyun $\operatorname{Han}^{1 凶}$ \\ Hang Sik Lyoo ${ }^{2}$ \\ Kyung Joon Min ${ }^{1}$ \\ Kyung Ho Kim ${ }^{3}$ \\ Perry Renshaw ${ }^{4}$ \\ 'Department of Psychiatry, \\ Chung Ang University \\ College of Medicine, Seoul, \\ ${ }^{2}$ Tanbang Elementary School, \\ Daejeon, Korea \\ ${ }^{3}$ Department of Molecular Biosciences \\ in the School of Veterinary Medicine, \\ University of California, Davis, \\ ${ }^{4}$ Brain Institute, University of Utah, \\ Salt lake City, Utah, USA
}

\section{$\square$ Correspondence}

Doug Hyun Han, MD, PhD

Department of Psychiatry,

Chung Ang University

College of Medicine,

65-207 Hangang-ro 3-ga, Yongsan-gu,

Seoul 156-755, Korea

Tel +82-2-748-9805

Fax $+82-2-792-8307$

E-mail hduk@yahoo.com

(c) This is an Open Access article distributed under the terms of the Creative Commons Attribution Non-Commercial License (http://creativecommons.org/licenses/by-nc/3.0) which permits unrestricted non-commercial use, distribution, and reproduction in any medium, provided the original work is properly cited.
Objective Environmental pollutants, especially environmental toxins (ET), may have the potential to disrupt neurodevelopmental pathways during early brain development. This study was designed to test our hypothesis that mothers with autism spectrum disorder (ASD) children would have less knowledge about ET and more chance to be exposed to ET than mothers with healthy children (MHC).

Methods One hundred and six biologic mothers with ASD children (MASD) and three hundred twenty four biologic mothers with healthy children MHC were assessed using two questionnaires asking about ET.

Results The total score in response to questions related to knowledge about ET in MHC was higher than that in MASD. The possibility of exposure to ET was higher in MASD than MHC. MASD showed higher sub-scale scores in terms of exposures to canned food, plastics, waste incinerators, old electronics, microwavable food, and textiles.

Conclusion The current results show that reduced knowledge about ET and greater exposure to ET may be associated with autism spectrum disorder. Psychiatry Investig 2010;7:122-127

Key Words Environmental toxins, Autism spectrum disorders, Child behaviors.

Received: December 18, 2009 Revised: April 20, 2010 Accepted: April 30, 2010

Available online: May 12, 2010

\section{Introduction}

Exposure to several environmental chemicals which are extensively used in industry, such as polybrominated diphenyl ethers (PBDEs), polychlorinated biphenyls (PCBs), bisphenol A (BPA), and polychlorinated dibenzo-p-dioxin (PCDD), during the perinatal period has been suggested to be a possible causal factor for abnormal development, especially during the brain growth spurt (BGS). ${ }^{1}$ The BGS usually begins during the third trimester of pregnancy and continues throughout the first two years of life. ${ }^{2}$ The neurotoxic properties of environmental toxins (ET) have well been documented in a number of animal and human studies. Some of those studies suggested that the prenatal exposure to PCBs and PCDD could affect the development of brain and endocrine system. ${ }^{3}$ PBDEs, a common flame retardant for furniture and electronics, have been reported to be associated with adverse brain development in animals. ${ }^{4,5}$ Many animal studies have noted that acute or repeated perinatal exposure to PBDEs may alter motor and cognitive function in newborn animals. ${ }^{6-8}$ It has been reported that PBDE exposure affects important proteins such as BDNF, CaMKII and GAP-43, biochemical substrates involved in neuronal survival, growth, and synaptogenesis. ${ }^{5}$ Another chemically stable and bio-accumulated ET, PCBs which are used in joint- sealing material, glue-linking double glazing, concrete, paint, and plaster have been reported to disrupt the developing brain circuits. PCBs were thought to be associated with learning disorders and attention deficit hyperactivity disorder (ADHD). ${ }^{9}$ Early accidental exposure to PCBs was observed in cognitive impairment and hyperactivity in infants. ${ }^{10}$ In addition, BPA is used in the manufacture of various consumer products including polycarbonate containers for storage of food and beverages. ${ }^{11}$ The result of a 
study suggested that BPA released from polycarbonate drinking bottles might be related to the abnormal development of cerebellar neurons in vitro. ${ }^{12}$

Although there has been a controversy regarding the precise timing of the neurodevelopmental changes in ASD, an abnormal pattern of brain growth in autism spectrum diseases (ASD) has been reported in developmental and neuroimaging studies. ${ }^{13,14}$ It has been reported that ASD children have reduced their head sizes at birth, but the head sizes increased excessively between 1-2 months and 6-14 months. ${ }^{13}$ A magnetic resonance imaging study by Schumann et al. ${ }^{14}$ noted that 2-4 year old children with ASD had larger brain volumes in frontal, cerebellar, and limbic regions of the brain. In addition, reduced connectivity of white matter in ventromedial prefrontal cortices, anterior cingulate gyrus, and superior temporal regions has been documented in an ASD study using diffusion tensor imaging (DTI). ${ }^{15}$ Compared to healthy controls, lower functional connectivity between left posterior superior temporal gyrus and left inferior gyrus has also been found in children with ASD. ${ }^{16}$

In a review of mouse model studies, the significant effect of ET to mouse phenotypes of autism such as anxiety, seizures, sleep disturbances and sensory hypersensitivity was suggested. ${ }^{17}$ It has been demonstrated that exposure to dietary peptides and xenobiotics, such as casein and ethyl mercury, may instigate autoimmune reactions in children with autism. ${ }^{18}$

In a study of public health strategies for reducing aflatoxin exposure, Strosnider et al. ${ }^{19}$ assessed the relationship between current knowledge of aflatoxin-contaminated food and morbidity in developing countries. In line with this report, we hypothesized that mothers with ASD children would have less knowledge about ET and more chance to be exposed to ET than mothers with healthy children (MHC).

\section{Methods}

\section{Subjects}

One hundred and six biologic mothers with an ASD child (MASD) were recruited from schools for mentally-handicapped children in Seoul, Chungju, and Chuncheon, South Korea. The children with autism spectrum disorders were diagnosed by a child psychiatrist and were confirmed by the Government, ministry for health, welfare and family affairs when they entered schools. Three hundred and twenty four biologic MHC were recruited as control subjects from elementary schools in Seoul, Chungju, and Chuncheon, South Korea. To screen psychiatric problems, the Symptom Checklist-90-Revision was administered. ${ }^{20}$ In both groups, mothers with a history of psychiatric disease and/or substance dependence were excluded. Between the MASD and MHC groups, there was no significant difference in age, mother's age during pregnancy, years of education, history of breast feeding, or history of social drinking (Table 1). The protocol for this study has been approved by the institutional review board of Chung-Ang Yong San Hospital in Seoul, Korea. And written informed consent was obtained from all subjects before the study began.

Table 1. Demographic characteristics

\begin{tabular}{lccc}
\hline & Mothers c ASD (106) & Mothers c healthy child $(324)$ & $\mathrm{t} / \chi^{2}, \mathrm{p}$ \\
\hline Maternal age & $40.2 \pm 4.2$ & $39.5 \pm 3.5$ & $1.43,0.15$ \\
Age at birth & $30.2 \pm 4.0$ & $29.7 \pm 3.5$ & $1.22,0.25$ \\
Education years & $14.1 \pm 2.8$ & $14.0 \pm 2.2$ & $0.54,0.58$ \\
Economic state (high/middle/low) & $19 / 53 / 34$ & $37 / 191 / 96$ & $3.88,0.14$ \\
Alcohol intake before pregnancy (yes/no) & $62 / 44$ & $187 / 137$ & $0.02,0.91$ \\
Alcohol intake during pregnancy (yes/no) & $97 / 9$ & $299 / 25$ & $0.07,0.84$ \\
Sex of child (male/female) & $71 / 35$ & $203 / 121$ & $0.47,0.49$ \\
Age of child & $8.9 \pm 1.7$ & $8.8 \pm 1.4$ & $0.91,0.36$ \\
Breast feeding (yes/no) & $19 / 87$ & $65 / 267$ & $0.14,0.78$ \\
CBCL-K & & & $8.5,<0.001$ \\
Aggression & $10.7 \pm 8.9$ & $4.5 \pm 4.9$ & $11.9,<0.001$ \\
Social withdrawal & $4.3 \pm 3.2$ & $1.2 \pm 1.8$ & $3.3,0.001$ \\
Somatic complaints & $2.5 \pm 3.5$ & $1.5 \pm 2.2$ & $4.2,<0.001$ \\
Emotional lability & $2.3 \pm 1.3$ & $1.4 \pm 1.5$ & $8.3,<0.001$ \\
Obsessive anxious & $7.3 \pm 5.9$ & $3.3 \pm 3.3$ & $5.5,<0.001$ \\
Delinquent & $1.9 \pm 2.4$ & $0.7 \pm 1.5$ & $2.4 \pm 2.5$ \\
Hyperactive & $5.9 \pm 3.9$ & $0.9 \pm 1.9$ & $9.1,<0.001$ \\
Psychotic & $3.7 \pm 3.4$ & $<0.001$ \\
\hline
\end{tabular}

Mothers c ASD: mothers with children with autism spectrum disorders, CBCL-K: Child Behavior Checklist Korean version 
Table 2. Questionnaires about environmental toxins

\begin{tabular}{|c|c|c|c|c|c|c|c|c|c|c|c|c|c|c|}
\hline \multirow[b]{4}{*}{ Canned food } & \multicolumn{7}{|c|}{ 1st questionnaire } & \multicolumn{7}{|c|}{ 2nd questionnaire } \\
\hline & \multicolumn{7}{|c|}{ How harmful are the following items? } & \multicolumn{7}{|c|}{$\begin{array}{l}\text { How much were you exposed to below } \\
\text { items during your pregnancy? }\end{array}$} \\
\hline & \multicolumn{7}{|c|}{ 1: never harmful - 7: severely harmful } & \multicolumn{7}{|c|}{ 1: never - 7: very much } \\
\hline & 1 & 2 & 3 & 4 & 5 & 6 & 7 & 1 & 2 & 3 & 4 & 5 & 6 & 7 \\
\hline Plastics & 1 & 2 & 3 & 4 & 5 & 6 & 7 & 1 & 2 & 3 & 4 & 5 & 6 & 7 \\
\hline Dairy product & 1 & 2 & 3 & 4 & 5 & 6 & 7 & 1 & 2 & 3 & 4 & 5 & 6 & 7 \\
\hline Newly built houses & 1 & 2 & 3 & 4 & 5 & 6 & 7 & 1 & 2 & 3 & 4 & 5 & 6 & 7 \\
\hline Waste incinerators & 1 & 2 & 3 & 4 & 5 & 6 & 7 & 1 & 2 & 3 & 4 & 5 & 6 & 7 \\
\hline Seafoods & 1 & 2 & 3 & 4 & 5 & 6 & 7 & 1 & 2 & 3 & 4 & 5 & 6 & 7 \\
\hline Amalgam & 1 & 2 & 3 & 4 & 5 & 6 & 7 & 1 & 2 & 3 & 4 & 5 & 6 & 7 \\
\hline Polyurethane foams & 1 & 2 & 3 & 4 & 5 & 6 & 7 & 1 & 2 & 3 & 4 & 5 & 6 & 7 \\
\hline Fast food & 1 & 2 & 3 & 4 & 5 & 6 & 7 & 1 & 2 & 3 & 4 & 5 & 6 & 7 \\
\hline Hot canned beverages & 1 & 2 & 3 & 4 & 5 & 6 & 7 & 1 & 2 & 3 & 4 & 5 & 6 & 7 \\
\hline Old electronics & 1 & 2 & 3 & 4 & 5 & 6 & 7 & 1 & 2 & 3 & 4 & 5 & 6 & 7 \\
\hline Microwaveable food & 1 & 2 & 3 & 4 & 5 & 6 & 7 & 1 & 2 & 3 & 4 & 5 & 6 & 7 \\
\hline Fatty meat & 1 & 2 & 3 & 4 & 5 & 6 & 7 & 1 & 2 & 3 & 4 & 5 & 6 & 7 \\
\hline Textiles & 1 & 2 & 3 & 4 & 5 & 6 & 7 & 1 & 2 & 3 & 4 & 5 & 6 & 7 \\
\hline
\end{tabular}

\section{Instruments}

All participants were assessed with two questionnaires. In the first group of questions (left column), fourteen questions addressed the extent of knowledge of the mothers about ET and their potential harm. In the second group of questions (right column), fourteen questions addressed the extent to which MASD or MHC were exposed to ET during the BGS period of their children. The format of questionnaires used in current research was similar to the questionnaires in Jang et al.' ${ }^{21}$ study. Each question in both questionnaires was rated with a sevenpoint Likert scale (Table 2). ${ }^{21}$ Of the fourteen questions, twelve asked about the possible exposure to ET whereas the other two concerned control items. Those twelve questions regarding possible exposure to PBDEs, PCBs, BPA and PCDD were selected based on the guidelines provided by the study 'Ministry of Environment for the Republic of Korea', which suggests that these four substances are the common ET in Korea. ${ }^{22}$ And two questions with control items included dairy products and seafoods which were known not to be specifically associated with common ET in Korea. ${ }^{22}$ The Child Behavior Checklist Korean version (K-CBCL) was used to assess behaviors of the children. ${ }^{23,24}$

\section{Analysis of data}

Demographic and clinical variables involving continuous and categorical data were compared using independent t-tests and chi-square tests, respectively. The knowledge about ET and the severity of exposure to ETs were also compared using independent t-tests. The correlation between the knowledge of ET, severity of exposure to ET, and child behavior was tested with
Pearson's correlation analysis. Statistical significance was twotailed and defined at an alpha level of 0.05 . The significance was defined at $\mathrm{p}=0.003(0.05 / 14)$ in the post hoc comparison of the knowledge of ET and the grade of exposure to toxin subscales. Statistica 6.0 was used for all computations.

\section{Results}

The kappa values (test-retest reliability) of questionnaires for knowledge regarding the possible toxicity and possible exposure were 0.449-0.613 and 0.450-0.690 ( $<<0.05)$, respectively. Cronbach's alpha (Internal consistency reliability) of twelve ET related questions for knowledge regarding the possible toxicity and exposure were 0.916 and 0.807 , respectively. Cronbach's alpha between twelve ET related items (knowledge/exposure) and two control items, dairy product and seafoods were $0.257 / 0.264$ and $0.269 / 0.287$, respectively.

The total score for twelve questions related to knowledge of ET in MHC (61.4 \pm 16.3$)$ was higher than that in MASD $(54.8 \pm 16.5)(\mathrm{t}=2.9, \mathrm{p}=0.001)$. The possibility of exposure to ET was also higher in MASD $(35.5 \pm 11.1)$ than in MHC $(29.4 \pm 8.4)(t=5.6, p<0.001)$. A post hoc analysis revealed that MHC showed greater knowledge regarding the possible toxicity of plastics $(\mathrm{t}=4.3, \mathrm{p}<0.001)$, newly built houses $(\mathrm{t}=4.5$, $\mathrm{p}<0.001)$, polyurethane foams $(\mathrm{t}=3.1, \mathrm{p}<0.002)$, fast food $(\mathrm{t}=$ 4.6, $\mathrm{p}<0.001)$, microwaveable food $(\mathrm{t}=3.2, \mathrm{p}=0.001)$, and textiles $(\mathrm{t}=3.3, \mathrm{p}=0.001)$ compared to MASD (Table 3$)$. In another post hoc analysis of questions about possible exposure to ET, MASD showed higher sub-scale scores in response to questions about canned food $(\mathrm{t}=4.21, \mathrm{p}<0.01)$, plastics $(\mathrm{t}=6.2$, 
Table 3. Knowledge and exposure of environmental toxins

\begin{tabular}{|c|c|c|c|c|c|c|}
\hline & \multicolumn{3}{|c|}{ Knowledge about ET } & \multicolumn{3}{|c|}{ Self reported exposure to possible ET } \\
\hline & MASD (106) & MHC (324) & $\mathrm{t}, \mathrm{p}$ & MASD (106) & MHC (324) & $\mathrm{t}, \mathrm{p}$ \\
\hline Canned food & $4.5 \pm 1.7$ & $4.8 \pm 1.9$ & $1.3,0.19$ & $3.0 \pm 1.3$ & $2.3 \pm 1.0$ & $5.3,<0.001^{*}$ \\
\hline Plastics & $4.8 \pm 1.8$ & $5.7 \pm 1.6$ & $4.3,<0.001^{*}$ & $4.2 \pm 1.6$ & $3.2 \pm 1.2$ & $6.2,<0.001^{*}$ \\
\hline Dairy product ${ }^{\dagger}$ & $3.9 \pm 1.8$ & $3.8 \pm 1.9$ & $0.6,0.6$ & $4.0 \pm 1.5$ & $3.9 \pm 1.5$ & $1.0,0.32$ \\
\hline Newly built houses & $4.8 \pm 2.1$ & $5.8 \pm 1.7$ & $4.5,<0.001^{*}$ & $2.3 \pm 1.7$ & $2.0 \pm 1.5$ & $1.7,0.12$ \\
\hline Waste incinerators & $5.3 \pm 1.9$ & $5.6 \pm 2.0$ & $1.4,0.16$ & $1.9 \pm 1.3$ & $1.5 \pm 1.0$ & $3.0,0.003^{*}$ \\
\hline Seafoods $^{\dagger}$ & $3.9 \pm 1.9$ & $3.8 \pm 1.9$ & $0.6,0.58$ & $4.3 \pm 1.7$ & $4.1 \pm 1.4$ & $0.9,0.38$ \\
\hline Amalgam & $3.6 \pm 1.9$ & $4.2 \pm 2.1$ & $2.1,0.03$ & $2.0 \pm 1.4$ & $2.0 \pm 1.4$ & $0.1,0.91$ \\
\hline Polyurethane foams & $3.9 \pm 1.8$ & $4.6 \pm 1.9$ & $3.1,0.002^{*}$ & $2.5 \pm 1.6$ & $2.1 \pm 1.3$ & $1.9,0.52$ \\
\hline Fast food & $4.8 \pm 1.8$ & $5.7 \pm 1.6$ & $4.6,<0.001^{*}$ & $3.2 \pm 1.6$ & $2.8 \pm 1.2$ & $2.4,0.02$ \\
\hline Hot canned beverages & $4.5 \pm 1.9$ & $4.8 \pm 2.0$ & $1.2,0.21$ & $2.6 \pm 1.8$ & $2.2 \pm 1.3$ & $2.7,0.007$ \\
\hline Old electronics & $4.1 \pm 2.0$ & $4.5 \pm 1.8$ & $1.7,0.09$ & $3.6 \pm 1.7$ & $3.0 \pm 1.4$ & $3.4,0.001^{*}$ \\
\hline Microwaveable food & $5.1 \pm 1.9$ & $5.7 \pm 1.7$ & $3.2,0.001^{*}$ & $3.2 \pm 1.6$ & $2.3 \pm 1.2$ & $5.7,<0.001^{*}$ \\
\hline Fatty meat & $4.7 \pm 1.7$ & $5.2 \pm 1.7$ & $2.3,0.03$ & $3.5 \pm 1.5$ & $3.1 \pm 1.2$ & $2.7,0.007$ \\
\hline Textiles & $4.1 \pm 1.9$ & $4.9 \pm 1.9$ & $3.3,0.001^{*}$ & $3.5 \pm 1.8$ & $2.8 \pm 1.3$ & $3.7,<0.001^{*}$ \\
\hline Total & $54.8 \pm 16.5$ & $61.4 \pm 16.3$ & $2.9,0.001^{*}$ & $35.5 \pm 11.1$ & $29.4 \pm 8.4$ & $5.6,<0.001^{*}$ \\
\hline
\end{tabular}

${ }^{*}$ statistically significant, ${ }^{\dagger}$ control items. MASD: mothers of children with autism spectrum disorders, MHC: mothers with healthy children, ET: environmental toxins, Total: sum of twelve questions for knowledge or possible exposure to ET except dairy product and seafood

$\mathrm{p}<0.001)$, waste incinerators $(\mathrm{t}=3.0, \mathrm{p}=0.003)$, old electronics $(\mathrm{t}=3.4, \mathrm{p}=0.001)$, microwavable food $(\mathrm{t}=5.7, \mathrm{p}<0.001)$, and textiles $(\mathrm{t}=3.7, \mathrm{p}<0.001)$ compared to MHC (Table 3$)$. There was no significant difference in exposure scores to control items including dairy product (knowledge: $\mathrm{t}=0.6, \mathrm{p}=0.6$, exposure: $\mathrm{t}=1.0, \mathrm{p}=0.32$ ) and seafoods (knowledge: $\mathrm{t}=0.6, \mathrm{p}=0.58$, exposure: $\mathrm{t}=0.9, \mathrm{p}=0.38$ ) in both questionnaires.

Across all study participants, there were no significant correlations between total scores of questions about knowledge of ET and questions about exposure to ET. However, in the MHC group, there was a negative correlation between total scores of questionnaires regarding knowledge of ET and possible exposure to ET $(\mathrm{r}=-0.221, \mathrm{p}<0.001)$.

The total scores of self-reported exposure to possible ET in MASD were significantly correlated with the K-CBCL subscale score child aggression ( $r=0.287, \mathrm{p}=0.004)$, somatic complaints $(r=0.292, p=0.004)$, emotional lability $(r=0.313, p=$ $0.002)$, and delinquencies $(\mathrm{r}=0.311, \mathrm{p}=0.002)$. In the post hoc analysis, aggression was associated with the exposure score of ETs in plastics $(\mathrm{r}=0.280, \mathrm{p}=0.006)$, old electronics $(\mathrm{t}=3.4, \mathrm{p}=$ $0.001)$, and microwavable food $(\mathrm{r}=0.281, \mathrm{p}<0.001)$. However, there was no significant correlation between self-reported exposure to possible ET in MHC and subscales of K-CBCL of their children.

\section{Discussion}

The etiology of ASD remains largely unknown. Although re- sults from genetic research including family and twin studies strongly suggest that genetic factors play an important role in the etiology of ASD, ${ }^{25}$ environmental factors may also have a crucial role in the expression of ASD phenotype. This is especially true when the influence of environmental factors converges with defective genes linked to autism risk. Since 1998, the Ministry of Environment of the Republic of Korea has begun to recognize the possible consequences of the exposure to critical toxins. These efforts have allowed people to recognize the harmful effects of ET more easily, 22 but a well-controlled research with a more systematic approach will be necessary.

As a first step toward the characterization of the association between ASD prevalence and ET, our current results indicate that mothers with ASD children had less knowledge about an increased possible exposure to ET, such as PBDEs, PCDD, PCBs and BPA. Furthermore, MHC showed a negative correlation between the knowledge of ET and the exposure to ET. In addition, reported exposure to ET was associated with severity of behavioral problems in children with autism spectrum disorders.

\section{PBDEs}

Extensive amounts of PBDE have been used as flame retardants and as ingredients in plastics, waste incinerators, old electronics (television set and computer), polyurethane foams and textiles. ${ }^{26,27}$ Kim et al. ${ }^{28}$ reported that the PBDE blood level in Koreans is higher than those reported in any other country. Increased lifetime exposure to PBDE is thought to disrupt the 
nerve differentiation. ${ }^{29,30}$

\section{PCDD}

Plastic goods and waste incinerators are reported to be associated with dioxin and its metabolite, PCDD. The incineration of municipal and industrial waste was regarded as an important source of PCDD in the Netherlands. "F1 "Fast food," also referred to as "junk food," was thought to contain pollutants such as PCDD, PBDEs, and PCBs. ${ }^{32}$ Peterson et al. ${ }^{33}$ have suggested that fetal and neonatal exposures to dioxin are also associated with prenatal mortality in mammals. Prenatal exposure to PCBs and PCDD might have a neurotoxic effect and delay the development of cognitive and motor abilities. ${ }^{34}$ During pregnancy, PCDD and PCBs are known to cross the placenta. ${ }^{35}$ Therefore, maternal exposure to ET during pregnancy can be one of the factors that determine the degree of fetal exposure.

\section{PCBs}

PCBs were widely used for many applications, especially as building materials and dielectric fluids in transformers and capacitors. Newly built houses, old electronics, and waste incinerators could be the sources of PCBs. An epidemiological study by Koopman-Esseboom et al..$^{36}$ said that maternal PCB exposure had a negative effect on cognitive development at 7 months of age. Kenet et al. ${ }^{37}$ suggested that perinatal exposure to noncoplanar PCBs could disrupt the development of primary auditory cortex in rats and might contribute to common developmental disorders. Huisman et al. ${ }^{38}$ have reported that preand postnatal exposure to PCBs and PCDD disrupted neurological development in newborn infants.

\section{BPA}

Various products including plastic goods, microwavable food, hot canned beverages, and dental sealants such as amalgam were thought to be associated with the exposure to BPA, because BPA is extensively used in epoxy and polycarbonate resins. ${ }^{12}$ Especially in high temperature, BPA can migrate from containers to food and beverages. ${ }^{39}$ Bindhumol et al. ${ }^{40}$ reported that BPA could induce oxidative stress, and Lin et al. ${ }^{41}$ suggested that BPA-induced reactive oxygen might have a cytotoxic effect on dopaminergic neuron.

The biological mechanism of neurotoxic effects of ET, such as PBDEs, PCDD, PCBs and BPA remains still unclear. Several studies have proposed that ET disrupts the thyroid hormone functions as an antagonist. ${ }^{42,43}$ Indeed, thyroid hormones were known to play an important role in the dendritic development of neurons. ${ }^{44}$ And other studies have suggested that ET interacts with neurotransmitter systems such as dopaminergic and cholinergic transmission and alters behavioral pattern of mice. ${ }^{7,45,46}$ Also, several studies have suggested that ET disrupts second messenger systems and increases oxidative stress and intracellular calcium level in neurons. ${ }^{47,48}$

\section{Study limitations}

There are a number of limitations to the results reported in this survey study. First, because the possibility of the exposure to ET was assessed with subjective scales and without biological evidence, a direct correlation between the cause and the effect of ET exposure on children with autism spectrum disorders was not shown. In addition, other possible etiologic factors than ET, such as the genetic polymorphism were not considered. Furthermore, an objective relationship between recognizing the importance of ET and reducing exposure was not determined by any objective method. Further studies are required to ascertain the biologic effects of ET exposure on the prevalence of autism spectrum disorders.

\section{Conclusions}

The exposure to ET, such as PBDEs, PCDD, PCBs and BPA, can be considered as candidate factors, which is associated with the diagnosis and behavior-aggravating factors in children with autism spectrum disorders. We cautiously suggest that education with respect to the serious risks of ET could have important public health consequences.

\section{REFERENCES}

1. Eriksson P, Ahlbom J, Fredriksson A. Exposure to DDT during a defined period in neonatal life induces permanent changes in brain muscarinic receptors and behaviour in adult mice. Brain Res 1992;582:277-281.

2. Davisson AN, Dobbing J. Applied neurochemistry. Oxford: Blackwell; 1968.

3. Vreugdenhil HJ, Slijper FM, Mulder PG, Weisglas-Kuperus N. Effects of perinatal exposure to PCBs and dioxins on play behavior in Dutch children at school age. Environ Health Perspect 2002;110:A593-A598.

4. Harrad S, Wijesekera R, Hunter S, Halliwell C, Baker R. Preliminary assessment of U.K. human dietary and inhalation exposure to polybrominated diphenyl ethers. Environ Sci Technol 2004;38:2345-2350.

5. Viberg H, Mundy W, Eriksson P. Neonatal exposure to decabrominated diphenyl ether (PBDE 209) results in changes in BDNF, CaMKII and GAP-43, biochemical substrates of neuronal survival, growth, and synaptogenesis. Neurotoxicology 2008;29:152-159.

6. Branchi I, Capone F, Vitalone A, Madia F, Santucci D, Alleva E, et al. Early developmental exposure to BDE 99 or Aroclor 1254 affects neurobehavioural profile: interference from the administration route. Neurotoxicology 2005;26:183-192.

7. Eriksson P, Viberg H, Jakobsson E, Orn U, Fredriksson A. A brominated flame retardant, 2,2',4,4',5-pentabromodiphenyl ether: uptake, retention, and induction of neurobehavioral alterations in mice during a critical phase of neonatal brain development. Toxicol Sci 2002;67:98-103.

8. Viberg H, Fredriksson A, Eriksson P. Changes in spontaneous behaviour and altered response to nicotine in the adult rat, after neonatal exposure to the brominated flame retardant, decabrominated diphenyl ether (PBDE 209). Neurotoxicology 2007;28:136-142.

9. Kuroda Y. Effects of endocrine disruptors on brain development. Development of novel assay systems for risk assessment. Environ Sci 2003; 10:23-33.

10. Chen YC, Guo YL, Hsu CC, Rogan WJ. Cognitive development of YuCheng ("oil disease") children prenatally exposed to heat-degraded PCBs. JAMA 1992;268:3213-3218.

11. CERHR. Interm NTP-CERHR report on the reproductive and developmental toxicity of bisphenol A. Available at: http://cerhr.niehs.nih. gov/chemicals/bisphenol/BPA. Accessed July 1, 2009. 
12. Le HH, Carlson EM, Chua JP, Belcher SM. Bisphenol A is released from polycarbonate drinking bottles and mimics the neurotoxic actions of estrogen in developing cerebellar neurons. Toxicol Lett 2008; 176:149156.

13. Courchesne E. Brain development in autism: early overgrowth followed by premature arrest of growth. Ment Retard Dev Disabil Res Rev 2004;10:106-111.

14. Schumann CM, Hamstra J, Goodlin-Jones BL, Lotspeich LJ, Kwon $\mathrm{H}$, Buonocore $\mathrm{MH}$, et al. The amygdala is enlarged in children but not adolescents with autism; the hippocampus is enlarged at all ages. J Neurosci 2004;24:6392-6401.

15. Barnea-Goraly N, Kwon H, Menon V, Eliez S, Lotspeich L, Reiss AL. White matter structure in autism: preliminary evidence from diffusion tensor imaging. Biol Psychiatry 2004;55:323-326.

16. Just MA, Cherkassky VL, Keller TA, Minshew NJ. Cortical activation and synchronization during sentence comprehension in high-functioning autism: evidence of underconnectivity. Brain 2004;127:1811-1821.

17. Crawley JN. Mouse behavioral assays relevant to the symptoms of autism. Brain Pathol 2007;17:448-459.

18. Vojdani A, Pangborn JB, Vojdani E, Cooper EL. Infections, toxic chemicals and dietary peptides binding to lymphocyte receptors and tissue enzymes are major instigators of autoimmunity in autism. Int J Immunopathol Pharmacol 2003;16:189-199.

19. Strosnider H, Azziz-Baumgartner E, Banziger M, Bhat RV, Breiman $\mathrm{R}$, Brune MN, et al. Workgroup report: public health strategies for reducing aflatoxin exposure in developing countries. Environ Health Perspect 2006;114:1898-1903.

20. Kim KI, Kim JW, Won HT. Korean manual of Symptom Checklist-90Revision. Seoul: Chung Ang Aptitude; 1984.

21. Chang EA, Park CY, Lim YW, Shin DC. A comparison of environmental risk perceptions between general public and experts. K J Environ Toxicol 2001;16:75-84.

22. Ryu JC. Overall review on endocrine disruptors. Kor J Pesticide Sci 2002;6:135-156.

23. Achenbach TM, Edelbrock CS. Manual for the Child Behavior Checklist and Revised Child Behavior Profile. Burlington, VT: University of Vermont, Department of Psychiatry; 1983.

24. Oh KJ, Lee HR, Hong KE. Child Behavior Checklist Korean version (KCBCL). Seoul: Seoul Central Research Center; 1997.

25. Cantor RM. Molecular genetics of autism. Curr Psychiatry Rep 2009; 11:137-142.

26. Hardy ML. The toxicology of the three commercial polybrominated diphenyl oxide (ether) flame retardants. Chemosphere 2002;46:757-777.

27. She J, Petreas M, Winkler J, Visita P, McKinney M, Kopec D. PBDEs in the San Francisco Bay Area: measurements in harbor seal blubber and human breast adipose tissue. Chemosphere 2002;46:697-707.

28. Kim BH, Ikonomou MG, Lee SJ, Kim HS, Chang YS. Concentrations of polybrominated diphenyl ethers, polychlorinated dibenzo-p-dioxins and dibenzofurans, and polychlorinated biphenyls in human blood samples from Korea. Sci Total Environ 2005;336:45-56.

29. Behnisch PA, Hosoe K, Sakai S. Bioanalytical screening methods for dioxins and dioxin-like compounds a review of bioassay/biomarker technology. Environ Int 2001;27:413-439.

30. Davis C, Bhana S, Shorrocks AJ, Martin FL. Oestrogens induce G(1) arrest in benzo[a]pyrene-treated MCF-7 breast cells whilst enhancing genotoxicity and clonogenic survival. Mutagenesis 2002;17:431-438.

31. Bremmer HJ. Sources of Dioxins in the Netherlands. (No. 730501014). Netherlands: Bilthoven; 1991.
32. Schecter A, Li L. Dioxins, dibenzofurans, dioxin-like PCBs, and DDE in U.S. fast food, 1995. Chemosphere 1997;34:1449-1457.

33. Peterson RE, Theobald HM, Kimmel GL. Developmental and reproductive toxicity of dioxins and related compounds: cross-species comparisons. Crit Rev Toxicol 1993;23:283-335.

34. Vreugdenhil HJ, Lanting CI, Mulder PG, Boersma ER, Weisglas-Kuperus N. Effects of prenatal PCB and dioxin background exposure on cognitive and motor abilities in Dutch children at school age. J Pediatr 2002;140:48-56.

35. Van Wijnen J, Van Bavel B, Lindstrom G, Koppe JG, Olie K. Placental transport of PCDDs and PCDFs in infants. Bayreuth: Eco informa press; 1990.

36. Koopman-Esseboom C, Weisglas-Kuperus N, de Ridder MA, Van der Paauw CG, Tuinstra LG, Sauer PJ. Effects of polychlorinated biphenyl/dioxin exposure and feeding type on infants' mental and psychomotor development. Pediatrics 1996;97:700-706.

37. Kenet T, Froemke RC, Schreiner CE, Pessah IN, Merzenich MM. Perinatal exposure to a noncoplanar polychlorinated biphenyl alters tonotopy, receptive fields, and plasticity in rat primary auditory cortex. Proc Natl Acad Sci U S A 2007;104:7646-7651.

38. Huisman M, Koopman-Esseboom C, Fidler V, Hadders-Algra M, van der Paauw CG, Tuinstra LG, et al. Perinatal exposure to polychlorinated biphenyls and dioxins and its effect on neonatal neurological development. Early Hum Dev 1995;41:111-127.

39. Le HH, Carlson EM, Chua JP, Belcher SM. Bisphenol A is release from polycarbonate drinking bottles and mimics the neurotoxic actions of estrogen in developing cerebellar neurons. Toxicol Lett 2008; 176:149-156.

40. Bindhumol V, Chitra KC, Mathur PP. Bisphenol A induces reactive oxygen species generation in the liver of male rats. Toxicology 2003;188: 117-124.

41. Lin Y, Zeng XG, Wu DS, Wang X. [Study on bisphenol A induced primary cultured mesencephalic neuronal cell injury by oxidative stress.] Wei Sheng Yan Jiu 2006;35:419-422.

42. Kimua-Kuroda J, Nagata I, Kuroda Y. Disrupting effects of hydroxypolychlorinated biphenyl (PCB) congeners on neuronal development of cerebellar Purkinje cells: a possible causal factor for developmental brain disorders? Chemosphere 2007;67:S412-S420.

43. Moriyama K, Tagami T, Akamizu T, Usui T, Saijo M, Kanamoto N, et al. Thyroid hormone action is disrupted by bisphenol A as an antagonist. J Clin Endocrinol Metab 2002;87:5185-5190.

44. Smith JW, Evans AT, Costall B, Smythe JW. Thyroid hormones, brain function and cognition: a brief review. Neurosci Biobehav Rev 2002;26: 45-60.

45. Viberg H, Fredriksson A, Eriksson P. Neonatal exposure to polybrominated diphenyl ether (PBDE 153) disrupts spontaneous behaviour, impairs learning and memory, and decreases hippocampal cholinergic receptors in adult mice. Toxicol Appl Pharmacol 2003;192:95-106.

46. Mariussen E, Fonnum F. The effect of brominated flame retardants on neurotransmitter uptake into rat brain synaptosomes and vesicles. Neurochem Int 2003;43:533-542

47. Kodavanti PR. Neurotoxicity of Persistent Organic Pollutants: Possible Mode(s) of Action and Further Considerations. Dose-Response 2006;3:273-305.

48. Sul D, Kim HS, Cho EK, Lee M, Kim HS, Jung WW, et al. 2,3,7,8TCDD neurotoxicity in neuroblastoma cells is caused by increased oxidative stress, intracellular calcium levels, and tau phosphorylation. Toxicology 2009;255:65-71. 